\title{
Mesangial Cell Immune Injury Synthesis, Origin, and Role of Eicosanoids
}

\author{
Elias A. Lianos," Barbara A. Bresnahan," and Cynthia Pan* \\ With the technical assistance of Beatrice Hucke and Shelley Dufek \\ Medical College of Wisconsin, ${ }^{*}$ Departments of Medicine and ${ }^{\ddagger}$ Pediatrics, Milwaukee, Wisconsin 53226
}

\begin{abstract}
The synthesis, cell origin, and physiologic role of eicosanoids were investigated in a model of mesangial cell immune injury induced by a monoclonal antibody against the rat thymocyte antigen Thy 1.1 also expressed in rat mesangial cells. A single intravenous injection of the antibody resulted in enhanced glomerular synthesis of thromboxane $(T x) B_{2}$, leukotriene (LT) $B_{4}$, and 12-hydroxyeicosatetraenoic acid (HETE), whereas that of $\mathrm{PGE}_{2}$ and $\mathrm{PGF}_{2} \alpha$ was either unaltered or impaired. The enhanced eicosanoid synthesis was associated with decrements in glomerular filtration rate (GFR) and renal blood flow (RBF). Complement activation mediated both the increments in $\mathbf{T x B}_{2}$, $\mathrm{LTB}_{4}$, and 12-HETE and the decrements in GFR and RBF. The decrements in GFR were abolished by the $T \times A_{2}$ receptor antagonist SQ-29,548. Although both neutrophiles and Ia (+) leukocytes infiltrated glomeruli, glomerular $\mathbf{L T B}_{4}$ originated mainly from the latter. Platelets entirely accounted for the enhanced 12-HETE synthesis in isolated glomeruli and to a lesser extent for that of $\mathbf{L T B}_{4}$ and $\mathrm{TxB}_{2}$. Glomerular $\mathrm{PGE}_{2}$ and $\mathrm{PGF}_{2} \alpha$ originated from mesangial cells as their impaired synthesis coincided with extensive mesangial cell lysis. The observations indicate that in mesangial cell immune injury vasoactive and proinflammatory eicosanoids originate from recruited or activated Ia $(+)$ leukocytes and platelets and may exert paracrine effects on mesangial cells. (J. Clin. Invest. 1991. 88:623631.) Key words: mesangial cell $\bullet$ nephritis $\bullet$ eicosanoids $\bullet$ leukocytes • platelets
\end{abstract}

\section{Introduction}

The Thy-1 gene is a member of the immunoglobulin "super family" of genes and is expressed in a number of different cell types (1). The expression product is a $17-\mathrm{kD}$ cell surface antigenic glycoprotein (the Thy- 1 antigen) that is expressed in thymocytes, young lymphocytes, and their precursor hematopoietic stem cells, in fibroblasts and in neurons of the central nervous system (1). Rat glomerular mesangial cells have also been shown to express the Thy-1.1 antigen (2). In Thy-1-bearing cells this antigen is anchored to the acyl chains of membrane phosphatidylinositol and can be cleaved by a phosphatidylino-

Address correspondence and reprint requests to Dr. Elias A. Lianos, Department of Medicine, Nephrology Division, Froedtert Memorial Lutheran Hospital, 9200 West Wisconsin Avenue, Milwaukee, WI 53226.

Received for publication 28 September 1990 and in revised form 21 March 1991.

J. Clin. Invest.

(c) The American Society for Clinical Investigation, Inc.

0021-9738/91/08/0623/09 \$2.00

Volume 88, August 1991, 623-631 sitol-specific phospholipase C (3). A monoclonal antibody $\left(E R_{4}, I g G 2 A\right)$, raised against the rat thymocyte antigenic determinant Thy 1.1 , binds to rat glomerular mesangial cells and induces a complement-dependent injury resulting in mesangial cell lysis, followed by a mesangioproliferative phase (4). This model of glomerular immune injury can, therefore, be regarded as the experimental equivalent of nephropathies involving primarily the glomerular mesangium, and provides the opportunity to investigate the biology of mesangial cell injury as it relates to synthesis of proinflammatory mediators and renal hemodynamic perturbations. We, therefore, investigated the biosynthesis, cell origin, and role of vasoactive and proinflammatory arachidonate cyclooxygenation and lipoxygenation products.

\section{Methods}

Induction of mesangial cell immune injury. Mesangial cell injury was induced by a single intravenous administration of the mouse monoclonal antibody $\left(\mathrm{ER}_{4}\right)$ raised against the rat thymocyte antigenic determinant Thy 1.1 and generously provided by Dr. W. Bagchus, Department of Pathology, University of Groningen, The Netherlands. This antibody (molecular weight $25 \mathrm{kD}$ ) binds to thymocytes, bone marrow cells, peripheral blood lymphocytes, and to mesangial cells, and also demonstrates complement binding capacity (4). Male Munich-Wistar rats (165-290 $\mathrm{g}$ body $\mathrm{wt}$ ) were employed and, in most experiments, two antibody doses were employed: a 2.5 and a $6 \mathrm{mg} / \mathrm{kg}$ body wt. Both doses induced proteinuria (urine protein excretion: $207 \pm 9 \mathrm{mg} / 24 \mathrm{~h}$ ) and glomerulonephritis. The 6-mg/ $/ \mathrm{kg}$ dose also induced decrements in glomerular filtration rate and renal blood flow (see below). Glomerular and mesangial cell lesions were assessed in cortical sections by routine methods of light and immunofluorescence microscopy. Light microscopy assessed changes in glomerular and mesangial cell morphology in 4-5- $\mu$ cortical sections stained with the Hematoxylin-Eosin and Periodic acid Schiff stains as well as the presence of blood-borne leukocytes in sections stained with the Giemsa stain. Immunofluorescence microscopy (direct) was performed in 7-8- $\mu$ cortical sections and assessed deposition and distribution of the ER 4 antibody using FITC-labeled goat anti-mouse IgG and of rat complement component $C_{3}$ using FITC-labeled goat anti-rat $C_{3}$. The presence of Ia $(+)$ cells was also assessed by direct immunofluorescence using an FITC-labeled mouse monoclonal antibody against the rat monocyte/macrophage Ia determinant (Sera-Lab, Sussex, England). The presence of Ia $(+)$ and bloodborne leukocytes (neutrophils) was expressed as number of cells per glomerulus (mean \pm SEM, $n=20$ glomeruli).

Biochemistry studies. These studies were performed at two early points (1 and $2 \mathrm{~h}$ ) and at two late points (day 4 and day 14) after ER. antibody administration. At these time points, animals were nephrectomized and the kidneys were placed in RPMI- 1640 at $4^{\circ} \mathrm{C}$. Glomeruli were isolated by differential sieving, suspended in $2 \mathrm{ml}$ of RPMI-1640, and incubated under constant stirring at $37^{\circ} \mathrm{C}$ for $30 \mathrm{~min}$. At the end of this incubation period, an aliquot of the medium (100-200 $\mu \mathrm{l})$ was sampled and assayed directly for $\mathrm{PGE}_{2}, \mathrm{PGF}_{2} \alpha$, and $\mathrm{TxB}_{2}$ using specific RIA for these eicosanoids as previously described (5). In the remaining glomerular suspension, the phospholipase $A_{2}$ activator $A_{23187}$ was added (final concentration $2 \mu \mathrm{M}$ ) in order to assess synthesis of the 
arachidonate lipoxygenation products 12-hydroxyeicosatetraenoic acid (HETE) ${ }^{1}$ and leukotriene (LT) $B_{4}$. A second incubation in the presence of $A_{23187}$ was performed at $37^{\circ} \mathrm{C}$ for $45 \mathrm{~min}$ and was terminated by the addition of $2 \mathrm{vol}$ of acidified absolute ethanol. After prolonged agitation at $4^{\circ} \mathrm{C}$, the ethanolic mixture of the glomerular suspensions was centrifuged in order to separate glomeruli and precipitated proteins. The supernatant was dried under vacuum, suspended in $1 \mathrm{ml}$ of methanol:water:acetic acid (64:34:2 vol/vol/vol), and injected in a gradient HPLC system in order to separate and isolate HETE and leukotrienes, as previously described (6). HPLC-isolated 12-HETE and $\mathrm{LTB}_{4}$ were subsequently measured using specific RIAs as previously described (6). The glomerular pellet was solubilized in $0.1 \mathrm{~N}$ sodium hydroxide and used for protein determination by a colorimetric method. Results were expressed in nanograms of eicosanoid/mg glomerular protein. Sensitivities and cross-reactivities of the RIAs employed for the above eicosanoids were previously assessed and reported (6). The antiserum for $\mathrm{PGE}_{2}$ was purchased from the Institute Pasteur (Paris, France). The antiserum for thromboxane $(\mathrm{Tx}) \mathrm{B}_{2}$ was a gift from Dr. W. Campbell (University of Texas Southwestern Medical School, Dallas, TX). The antiserum for $\mathrm{PGF}_{2} \alpha$ was a gift from Dr. A. Hassid (New York Medical College, Valhalla, NY). The antiserum for $\mathrm{LTB}_{4}$ was generously provided by Dr. A. Ford-Hutchinson (MerckFrosst/Canada, Dorval, Quebec, Canada). The antibody for 12-HETE was generously provided by Dr. L. Levine (Brandeis University, Waltham, MA).

Physiology studies. These studies assessed the effect of intravenous $\mathrm{ER}_{4}$ antibody administration on changes in glomerular filtration rate (GFR) and renal blood flow (RBF). Animals were anesthetized with intraperitoneal thiobutabarbitol (Inactin; Byk, Gulden Konstanz, FRG), $12-15 \mathrm{mg} / 100 \mathrm{~g}$ body wt, and maintained at $37^{\circ} \mathrm{C}$ by warming on a constant temperature table. After tracheostomy, a catheter was placed in the right jugular vein for infusion of $2 \%$ albumin in $0.9 \%$ sodium chloride at a rate of $20 \mathrm{ml} / \mathrm{kg}$ per $\mathrm{h}$ throughout the experiment. Tritiated inulin, $0.5 \mu \mathrm{Ci} / \mathrm{ml}$, was added to the infusion solution for measurement of GFR. The right femoral artery was cannulated for measurement of systemic blood pressure via a transducer connected to a digital pressure monitor and for collection of blood samples. Catheters were inserted into the right and left ureters for urine collection. A flow probe (1.5-2.0 $\mathrm{mm}$ ) was placed around the left renal artery and RBF was measured using an electromagnetic flow meter (model 501; Carolina Instruments, King, NC). After completion of surgery and a 60-min stabilization period, two baseline clearance periods $(15 \mathrm{~min}$ each) were obtained. Animals subsequently received a single intravenous injection of ER $\mathrm{R}_{4}$ antibody $(6 \mathrm{mg} / \mathrm{kg}$ ) or mouse IgG (controls, 6 $\mathrm{mg} / \mathrm{kg}$ ) and urine and plasma samples were collected for determination of GFR at $1 \mathrm{~h}$ after administration of $E_{\mathbf{4}}$.

In a second group of animals, GFR and RBF were assessed after decomplementation in order to determine the role of complement in mediating the $\mathrm{ER}_{4}$ antibody-induced changes in these parameters. Decomplementation was achieved by the intraperitoneal injection of cobra venom factor (CVF; Cordis, Miami, FL) purified by ion exchange and gel filtration chromatography (7). $100 \mathrm{U}$ per $100 \mathrm{~g}$ body wt was administered in four divided doses over the 24-h period preceeding measurements of GFR and RBF. Animals were subsequently instrumented and GFR and RBF were measured as described above. Upon completion of these measurements rats were nephrectomized and glomeruli were isolated for assessment of eicosanoid synthesis as described above. Systemic decomplementation was assessed by a modified hemolytic assay, performed in serum samples obtained from the tail vein at baseline and before initiation of the physiologic studies. To perform the assay, sensitized sheep red blood cells, $1 \times 10^{9} \mathrm{cells} / \mathrm{ml}$, were incubated with varying dilutions of serum samples at $37^{\circ} \mathrm{C}$ for $1 \mathrm{~h}$ and subse-

1. Abbreviations used in this paper: CVF, cobra venom factor; GFR, glomerular filtration rate; GBM, glomerular basement membrane; HETE, hydroxyeicosatetraenoic acid; LT, leukotriene; PG, prostaglandin; RBF, renal blood flow; Tx, thromboxane. quently centrifuged for $10 \mathrm{~min}$. Absorbance (spectrophotometry) was measured at $\lambda=540 \mathrm{~nm}$. Decomplementation was considered complete when absorbance readings from CVF-treated animals were less than $5 \%$ baseline samples. Decomplementation was also confirmed by the absence of immunofluorescence staining for glomerular $C_{3}$ deposits.

In a third group of animals, the $\mathrm{ER}_{\mathbf{4}}$ antibody was given after pretreatment with the $\mathrm{TxA}_{2}$ receptor antagonist SQ-29,548 ([1S-[1 $\alpha, 2 \beta$ (5Z), 3 $\beta, 4 \alpha]]-7-[-3-[[2-[($ phenylamino) carbonyl] hydrazino] methyl]7-oxabicyclo [2.2.1] hept-2-yl]-5-heptenoic acid; Squibb Institute for Medical Research, Princeton, NJ). This compound was given as an intravenous bolus of $2 \mathrm{mg} / \mathrm{kg}$, followed by a constant infusion of 2 $\mathrm{mg} / \mathrm{kg}$ per $\mathrm{h}$ for $20 \mathrm{~min}$ before the administration of $\mathrm{ER}_{4}$ antibody $(6$ $\mathrm{mg} / \mathrm{kg}$ ). GFR and RBF were determined before the infusion of SQ29,548 , before $\mathrm{ER}_{4}$ antibody, and at $1 \mathrm{~h}$ after infusion of $\mathrm{ER}_{4}$. Upon completion of these measurements, glomeruli were isolated for analysis and quantification of eicosanoids as described above.

Leukocyte and platelet depletion studies. Glomerular Ia (+) leukocytes were depleted by the use of a whole animal $x$ irradiation protocol as previously described (8). Specifically, animals were subjected to 250 $\mathrm{KVp}$ orthovoltage $\mathrm{x}$ rays with a half value of $1 \mathrm{~mm} \mathrm{Cu}$ at a dose rate of $133 \mathrm{rad} / \mathrm{min}$ for a total dose of 900-1,100 rad, using parallel opposed fields. Kidneys were shielded with 6-mm thick lead blocks that covered the kidneys within $5 \mathrm{~mm}$ margins. Positioning of the blocks was verified with diagnostic $x$ rays done simultaneously with treatment (port fields). Dosimetry was done in a plexiglass phantom using a Farmertype ionization chamber. The effect of $x$ irradiation was assessed on peripheral leukocyte counts determined by an automated hematology analyzer (Coulter Electronics, Hialeah, FL) before administration of $\mathrm{ER}_{4}$ and on glomerular Ia (+) cells, neutrophil counts, and $\mathrm{LTB}_{4}$ synthesis at $2 \mathrm{~h}$ after $\mathrm{ER}_{\mathbf{4}}$. These studies employed three groups of rats that were studied at 24,72 , and $96 \mathrm{~h}$ after the $\mathrm{x}$ irradiation dose.

To deplete animals of circulating platelets, a rabbit anti-rat thrombocyte immune serum was employed (Accurate Co., Westbury, NY). A single intraperitoneal injection of $1.5 \mathrm{ml}$ of this serum resulted in marked and selective systemic platelet depletion within 18-24 $\mathrm{h}$ and was associated with prolongation in the bleeding time. After platelet depletion was confirmed in each animal by an automated hematology

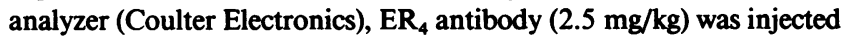
and glomeruli were isolated $2 \mathrm{~h}$ later for determination of eicosanoid synthesis as described above.

In vitro eicosanoid synthesis. To assess whether binding of anti-Thy 1 antibody in the glomerular mesangium in vitro induces eicosanoid synthesis, glomeruli isolated from normal animals were subjected to mild enzymatic permeabilization in Hank's balanced salt solution containing $1 \%$ Hepes, collagenase Type II, $50 \mathrm{U} / \mathrm{ml}$ (Sigma Chemical Co., St. Louis, MO), and DNAse $0.01 \%$ (Sigma Chemical Co.). After washing off the permeabilization solution, glomeruli were incubated with $\mathrm{ER}_{4}$ antibody $(2 \mathrm{mg} / \mathrm{ml} ; n=4)$ or mouse IgG $(2 \mathrm{mg} / \mathrm{ml} ; n=4)$ in the presence of $10 \%$ rat serum or plasma as a source of complement. Incubations were performed at $37^{\circ} \mathrm{C}$ for $45 \mathrm{~min}$ in a manner similar to that employed in glomeruli isolated from animals that had received $\mathbf{E R}_{\mathbf{4}}$ injections. Binding of $E R_{4}$ antibody and of rat complement $C_{3}$ to the glomerular mesangium was documented by immunofluorescence microscopy in an aliquot of glomeruli at the end of the incubations. Glomerular incubations were terminated by the addition of $2 \mathrm{vol}$ of absolute ethanol, and extracts were processed for isolation and quantification of $\mathrm{LTB}_{4}$ and 12-HETE using HPLC and RIA as described above.

\section{EXPERIMENTAL GROUPS}

1. Time course studies. Animals receiving $2.5 \mathrm{mg} / \mathrm{kg}$ of antibody $\mathbf{E R}_{4}$ and killed at $1 \mathrm{~h}(n=6), 2 \mathrm{~h}(n=10), 4 \mathrm{~d}(n=4)$, and $14 \mathrm{~d}(n=4)$ after antibody administration. Parallel controls receiving mouse IgG and studied at $1 \mathrm{~h}(n=5), 2 \mathrm{~h}(n=10), 4 \mathrm{~d}(n=8)$, and $14 \mathrm{~d}(n=4)$.

2. Physiology studies. (a) Animals receiving $\mathrm{ER}_{4}$ antibody $6 \mathrm{mg} / \mathrm{kg}$ $(n=8)$ or nonimmune mouse IgG (controls, $n=6)$ and studied at $1 \mathrm{~h}$. (b) Decomplemented animals receiving $\mathrm{ER}_{4}$ antibody $6 \mathrm{mg} / \mathrm{kg}(n=8)$ and decomplemented controls receiving nonimmune mouse $\operatorname{IgG}(n$ 
$=6$ ) and studied at $1 \mathrm{~h} .(c)$ Animals pretreated with the $\mathrm{TxA}_{2}$ receptor antagonist SQ-29,548, subsequently given $\mathrm{ER}_{4}$ antibody $6 \mathrm{mg} / \mathrm{kg}$ ( $n$ $=6$ ) and studied at $1 \mathrm{~h}$.

3. Studies in $x$ irradiated animals. These were performed at $24 \mathrm{~h}$ ( $n$ $=6)$, at $72 \mathrm{~h}(n=6)$, or at $96 \mathrm{~h}(n=6)$ after $\mathrm{x}$ irradiation. At these time points animals received $\mathrm{ER}_{4}$ antibody $(2.5 \mathrm{mg} / \mathrm{kg})$ and glomerular eicosanoid synthesis was assessed $2 \mathrm{~h}$ later.

4. Platelet depletion studies. Animals received a single injection of anti-thrombocyte serum $18-24 \mathrm{~h}$ before $\mathrm{ER}_{4}$ antibody $(2.5 \mathrm{mg} / \mathrm{kg} ; n$ $=6$ ). Glomerular eicosanoid synthesis was assessed at $2 \mathrm{~h}$ after injection of ER.

Statistical analyses employed the two-way analysis of variance for repeated measurements followed by a Duncan multiple range test and the Student's $t$ test for unpaired observations, as dictated by the experimental designs. Results were expressed as mean \pm SEM.

\section{Results}

Effects of $E R_{4}$ on glomerular histopathology. Fig. 1 demonstrates glomerular deposition of the monoclonal antibody $\mathrm{ER}_{4}$ at $1 \mathrm{~h}$ (Fig. $1 \mathrm{~A}$ ) and $14 \mathrm{~d}$ (Fig. $1 \mathrm{~B}$ ) after a single intravenous injection. The antibody initially localized in the glomerular mesangium (Fig. $1 A$ ). It subsequently redistributed towards peripheral glomerular capillary loops (Fig. 1 B). Fig. 2 demonstrates the presence of glomerular Ia $(+)$ cells in a control glomerulus (Fig. $1 \mathrm{~A}$ ), at $2 \mathrm{~h}$ (Fig. $2 \mathrm{~B}$ ), and on day 14 (Fig. $2 \mathrm{C}$ ) after a single intravenous injection of the $\mathrm{ER}_{4}$ antibody. There was an increase in $\mathrm{Ia}(+)$ cells throughout the glomerulus at $2 \mathrm{~h}$ and a sustained increment in these cells on day 14, at which point their location was peripheral. Fig. 3 demonstrates the changes in glomerular cellularity at various time points after $\mathrm{ER}_{\mathbf{4}}$ antibody administration. Increased cellularity was noted at 1 to $2 \mathrm{~h}$ (Fig. $3 \mathrm{~B}$ ) compared with control (Fig. $3 \mathrm{~A}$ ). On day 4 (Fig. $3 C$ ), glomerular hypocellularity with marked absence of mesangial cells was apparent. On day 14 (Fig. $3 \mathrm{D}$ ), glomerular cellularity recovered and there was also an increase in mesangial matrix.

Effects of ER 4 on glomerular eicosanoid synthesis: correlation with leukocyte infiltration. In Fig. 4 the changes in glomerular synthesis of $\mathrm{TxB}_{2}, \mathrm{PGE}_{2}$, and $\mathrm{PGF}_{2} \alpha$ compared with pooled synchronous controls are shown at the various time points after a single intravenous administration of $E_{4}$ antibody $(2.5 \mathrm{mg} / \mathrm{kg})$. There was a progressive and sustained increment in $\mathrm{TxB}_{2}$ that spanned all time points of study. In contrast, the synthesis of $\mathrm{PGE}_{2}$ and PGF $2 \alpha$ progressively declined and reached a nadir on day 4 . The synthesis of these two eicosanoids subsequently recovered (day 14) to control levels.

In Fig. 5 the glomerular synthetic profiles of $\mathrm{LTB}_{4}$ and 12HETE, at the various time points after a single intravenous injection of $\mathrm{ER}_{4}(2.5 \mathrm{mg} / \mathrm{kg})$, are shown in parallel with $\mathrm{LTB}_{4}$ and 12-HETE values obtained in synchronous controls. The synthesis of 12-HETE in animals receiving ER $_{4}$ was signifcantly enhanced at $2 \mathrm{~h}$ after antibody administration and remained increased at statistically significant levels at all subsequent time points compared with synchronous controls. In contrast to 12-HETE, significant increments in glomerular LTB $_{4}$ synthesis occurred earlier $(1 \mathrm{~h})$ but spanned a shorter period of time and returned toward control levels on day 4. $\mathrm{LTB}_{4}$ synthesis remained significantly higher than synchronous controls on day $4(0.51 \pm 0.10$ vs. $0.24 \pm 0.04 ; P<0.05)$ and was no different than controls on day 14. Fig. 6 demonstrates changes in glomerular Ia ( + ) and neutrophil cell counts.
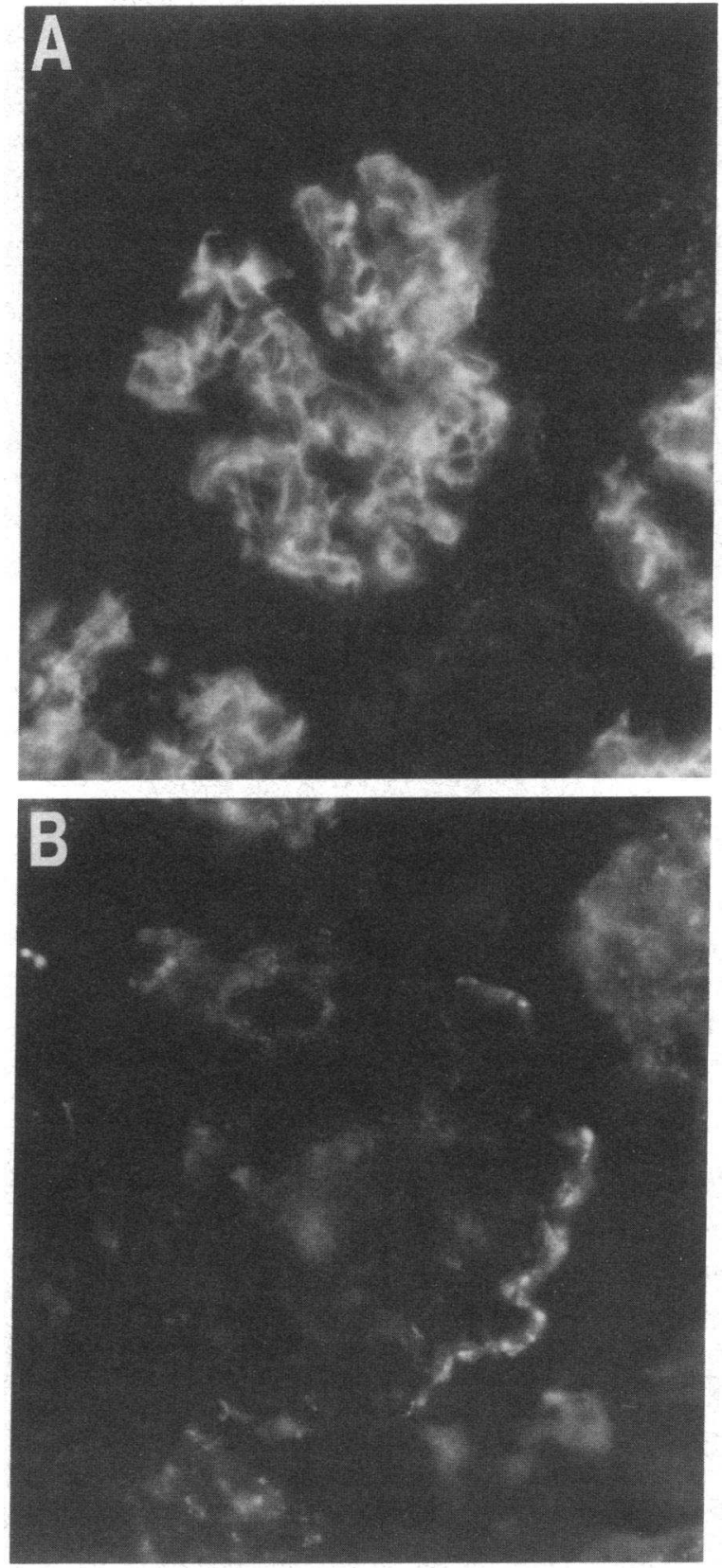

Figure 1. Immunofluorescence microscopy employing FITC-labeled goat anti-mouse IgG demonstrating glomerular $\mathrm{ER}_{\mathbf{4}}$ antibody deposition after a single intravenous dose. The antibody deposits in the mesangium at $1 \mathrm{~h}(A)$, with subsequent localization toward peripheral glomerular capillary loops on day $14(B)$.

Counts of both cell types were significantly higher at all time points compared with synchronous controls. Whereas the increments in glomerular 12-HETE and $\mathrm{LTB}_{4}$ were temporarily associated with the increments in glomerular $\mathrm{Ia}(+)$ and neutrophil cell counts at 1 and $2 \mathrm{~h}$ after administration of $\mathrm{ER}_{4}$ (Figs. 5 and 6), at later time points (days 4 and 14), LTB $_{4}$ values returned toward control levels (Fig. 5) despite a sustained increase in glomerular Ia (+) cell and neutrophil counts (Fig. 6). 12-HETE synthesis remained significantly increased at all time points. 

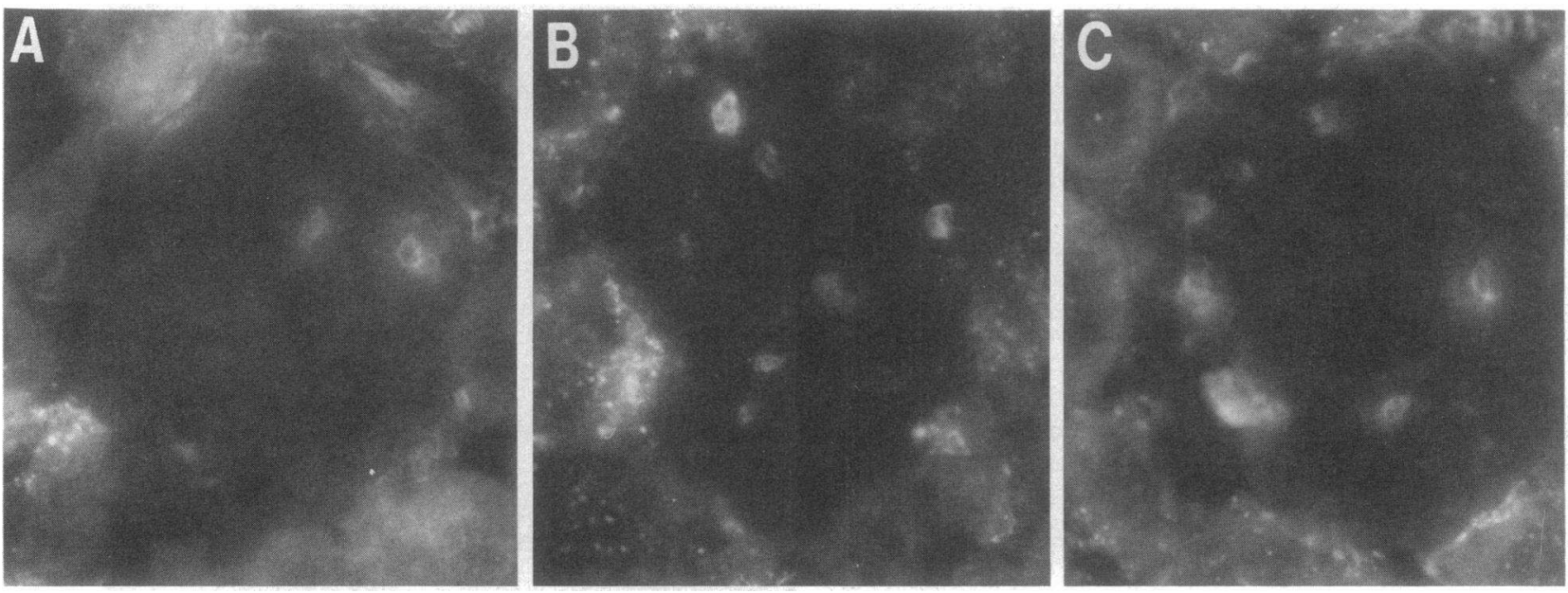

Figure 2. Immunofluorescence localization of glomerular Ia (+) cells in a control glomerulus $(A)$, at $2 \mathrm{~h}(B)$, and on day $14(C)$ after $\mathrm{ER}_{4}$ administration.

Effects of $x$ irradiation and of platelet depletion on glomerular eicosanoid synthesis. Table I demonstrates the correlation between glomerular $\mathrm{LTB}_{4}$ synthesis and glomerular neutrophil and Ia $(t)$ cell counts determined $2 \mathrm{~h}$ post-ER 4 and peripheral leukocyte counts assessed before $\mathrm{ER}_{4}$ administration in the three groups of animals studied at 24,72 , and $96 \mathrm{~h}$ after $\mathrm{x}$ irradiation dose. Peripheral leukopenia and a relative reduction in glomerular neutrophils after $\mathrm{x}$ irradiation were present in all groups. Post-ER 4 glomerular LTB $_{4}$ synthesis was signifi- cantly reduced only in glomerular preparations isolated from animals studied $96 \mathrm{~h}$ after $\mathrm{x}$ irradiation. In this group glomerular Ia $(+)$ cell counts were also abolished. In the groups studied 24 and 72 h post-x irradiation, although marked peripheral leukopenia and glomerular reduction of neutrophils were present, glomerular $\mathrm{LTB}_{4}$ synthesis measured $2 \mathrm{~h}$ post-ER $\mathrm{E}_{4}$ was not different compared with levels obtained in glomeruli isolated from nonirradiated rats studied $2 \mathrm{~h}$ after $\mathrm{ER}_{4}$ antibody administration (Table I).
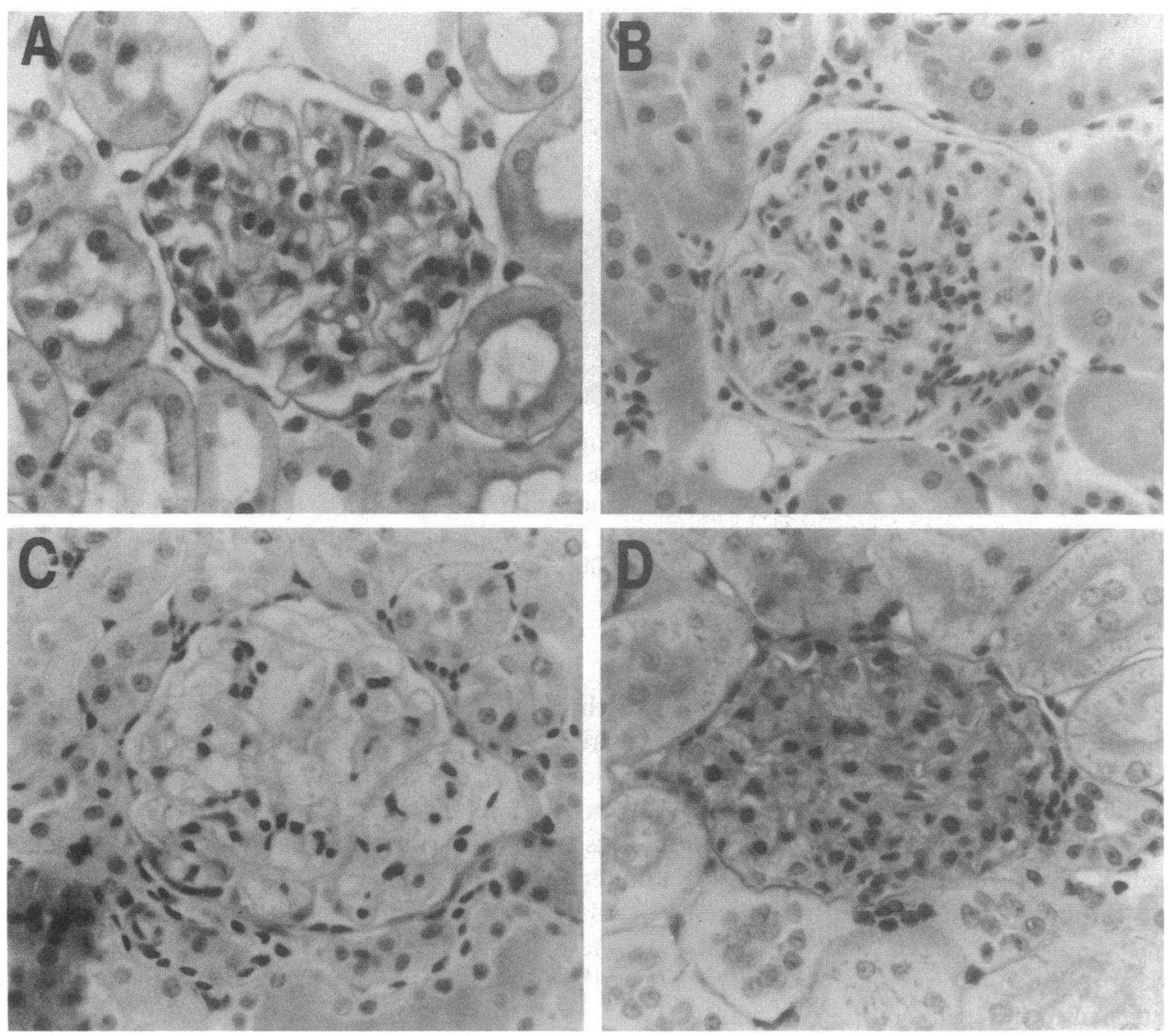

Figure 3. Light microscopy demonstrating changes in glomerular cellularity after a single administration of ER 4 antibody. $(A)$ Control glomerulus; $(B) 2 \mathrm{~h}$ post-ER $(C)$ day 4 , post-ER ${ }_{4} ;(D)$ day 14 , post-ER $\mathbf{4}$. 


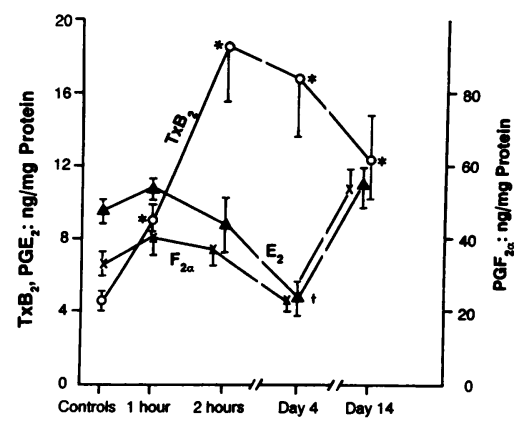

Figure 4. Effects of $\mathrm{ER}_{4}$ administration $(2.5 \mathrm{mg} /$ $\mathrm{kg}$ ) on glomerular $\mathrm{TxB}_{2}$, $\mathrm{PGE}_{2}$, and PGF2 $\alpha$ synthesis compared with pooled synchronous controls. There was no difference in the synthesis of these eicosanoids among controls at the various time points. There is a dichotomy in synthetic profiles of these three eicosanoids most notable on day $4 .{ }^{*} P<0.05$, $\mathrm{TxB}_{2}$ compared with pooled controls. $\uparrow P<0.05, \mathrm{PGE}_{2}$ and $\mathrm{PGF}_{2 \alpha}$ compared with pooled controls.

The effect of platelet depletion and of $\mathrm{x}$ irradiation on glomerular $\mathrm{TxB}_{2}, 12-\mathrm{HETE}$, and $\mathrm{LTB}_{4}$ synthesis assessed at $2 \mathrm{~h}$ after administration of $\mathrm{ER}_{4}(2.5 \mathrm{mg} / \mathrm{kg})$ is shown in Fig. 7. The $\mathrm{ER}_{4}$-induced increments in glomerular 12-HETE synthesis were abolished in the platelet-depleted group compared with the group that received $\mathrm{ER}_{4}$ antibody alone (Fig. 7). In this group, glomerular $\mathrm{TxB}_{2}$ and $\mathrm{LTB}_{4}$ synthesis were also significantly reduced; however, they remained significantly higher compared with control values. In the $x$ irradiated group ( $96 \mathrm{~h}$ postirradiation), glomerular $\mathrm{TxB}_{2}$ and 12-HETE synthesis were not significantly different compared with the group that received $\mathrm{ER}_{4}$ antibody alone. In contrast, $\mathrm{LTB}_{4}$ synthesis was significantly reduced.

The antiplatelet antibody employed markedly reduced circulating platelet counts (from $929 \pm 37$ to $8.3 \pm 2.1 \times 10^{3}$ per $\mu$; $n=6$ ) and had an insignificant effect on circulating leukocyte counts (from $10.9 \pm 0.8 \times 10^{3}$ to $8.6 \pm 1.3 \times 10^{3}$ per $\mu \mathrm{l} ; n=6$ ) assessed at $18 \mathrm{~h}$ after a single intraperitoneal injection of the antibody. $\mathrm{X}$ irradiation had no effect on circulating platelet counts assessed at $96 \mathrm{~h}\left(940 \pm 15 \times 10^{3} / \mu \mathrm{l}\right)$ or on serum complement assessed by hemolytic assay at the same time point (hemolysis of sensitized sheep RBCs measured spectrophotometrically as hemoglobin absorbance units: base line $=0.700 \pm 0.005$ vs. post-x irradiation $=0.727 \pm 0.024$ ).

In vitro effect of $E R_{4}$ antibody on glomerular eicosanoid synthesis. Fig. 8 demonstrates binding of ER $\mathrm{E}_{4}$ antibody (Fig. 8 $A$ ) and of rat $\mathrm{C}_{3}$ (Fig. $8 \mathrm{~B}$ ) in isolated enzymatically permeabilized glomeruli incubated with the monoclonal antibody $\mathrm{ER}_{4}$ $(2 \mathrm{mg} / \mathrm{ml}$ ) in the presence of $10 \%$ rat serum (source of complement). Fig. $8 C$ is a control glomerulus incubated with mouse

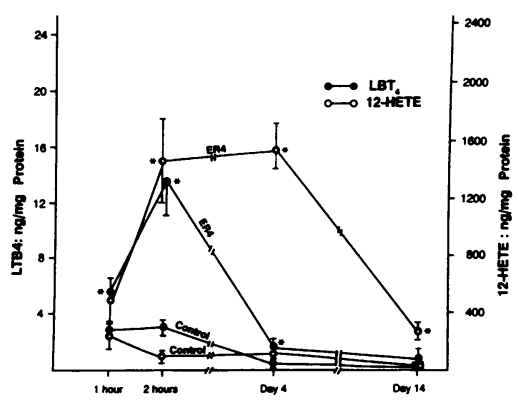

Figure 5. Effects of $\mathrm{ER}_{4}$ administration $(2.5 \mathrm{mg} /$ $\mathrm{kg}$ ) on glomerular $\mathrm{LTB}_{4}$ and 12-HETE synthesis compared with synchronous controls. Significant increments in 12HETE synthesis occurred at $2 \mathrm{~h}$ after ER, administration and were sustained on days 4 and 14. Significant incre-

ments in $\mathrm{LTB}_{4}$ synthesis occurred at $1,2 \mathrm{~h}$, and $4 \mathrm{~d}$ and they were no different than controls on day 14 .

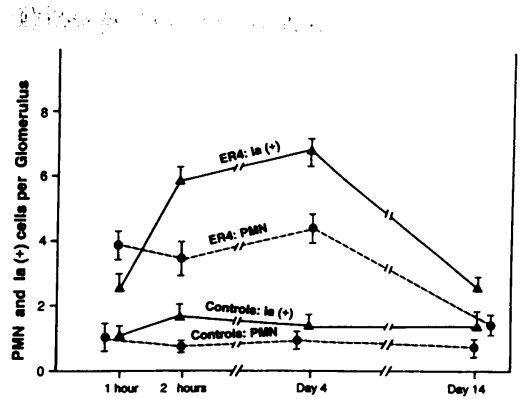

Figure 6. Changes in glomerular Ia $(+)$ cell and neutrophil (PMN) counts at $1 \mathrm{~h}, 2 \mathrm{~h}, 4 \mathrm{~d}$, and $14 \mathrm{~d}$. The Ia $(+)$ and neutrophil cell counts were significantly higher at all time points compared with synchronous controls.

IgG and stained for rat $C_{3}$. There was no change in glomerular $\mathrm{LTB}_{\mathbf{4}}$ synthesis in permeabilized glomeruli incubated with $\mathrm{ER}_{\mathbf{4}}$ antibody compared with control glomeruli incubated with mouse IgG $\left(\mathrm{LTB}_{4}: 0.9 \pm 0.2 \mathrm{ng} / \mathrm{mg}\right.$ glomerular protein in glomeruli incubated with $\mathrm{ER}_{4}$ and $1.7 \pm 0.2 \mathrm{ng} / \mathrm{mg}$ glomerular protein in glomeruli incubated with mouse $\mathrm{IgG}$ ). Because the rat serum used as a source of complement was found to contain high levels of 12 -HETE $(866 \mathrm{ng} / \mathrm{ml}$ of serum containing medium), two additional experiments using rat plasma as a complement source were performed in order to assess changes in glomerular 12-HETE synthesis in response to $\mathrm{ER}_{\mathbf{4}}$ binding. The levels of 12-HETE in rat plasma containing media were 47 $\mathrm{ng} / \mathrm{ml}$. In permeabilized glomeruli incubated with $\mathrm{ER}_{4}(2 \mathrm{ng} /$ $\mathrm{ml}$ ) in the presence of $10 \%$ rat plasma 12-HETE synthesis was $206 \mathrm{ng} / \mathrm{mg}$ glomerular protein. In control glomeruli incubated with mouse IgG 12-HETE synthesis was $260 \mathrm{ng} / \mathrm{mg}$ protein.

Effects of $E R_{4}$ on GFR and RBF: role of complement and of $T x$ receptor antagonism. Fig. 9 demonstrates the effect of complement depletion and of thromboxane receptor antagonism with SQ-29,548 on $\mathrm{ER}_{4}$ antibody-induced decrements in GFR and RBF. The glomerular eicosanoid synthetic profiles corresponding to the four groups of animals studied and determined upon completion of the GFR and RBF measurements are shown in Table II. In both the complement-depleted group and the SQ-29,548-treated group the decrements in GFR and RBF were ameliorated to levels not different from each other and significantly higher than the group receiving $\mathrm{ER}_{4}$ alone. In the SQ-29,548-pretreated rats, GFR and RBF values were no different compared with the decomplemented group of rats receiving mouse IgG (controls). In the decomplemented group receiving $\mathrm{ER}_{4}$, the glomerular synthesis of $\mathrm{TxB}_{2}, \mathrm{LTB}_{4}$, and 12-HETE were significantly lower compared with the complement replete group receiving $\mathrm{ER}_{4}$ (Table II). In the SQ-29,548pretreated group the synthesis of these eicosanoids was no different than the group receiving $\mathrm{ER}_{\mathbf{4}}$ alone.

\section{Discussion}

Enhanced eicosanoid synthesis in isolated glomeruli has been demonstrated in various forms of experimental and clinical glomerulopathies. Studies have focused on identifying the type of eicosanoid(s) synthesized after initiation of immune injury and their role in mediating vasoactive and proinflammatory events occurring in the progression of injury. Increased synthesis of both arachidonate cyclooxygenation and lipoxygenation metabolites has been demonstrated (9). Of the former, increased glomerular synthesis of thromboxane has been consistently shown in most forms of antibody-mediated renal injury and has been implicated in effecting adverse hemodynamic effects such as decrements in GFR and RBF (9). Of the arachi- 
Table I. Effect of X-Irradiation on Peripheral Leukocyte Counts (WBC) before ER $R_{4}$ Administration and on Glomerular Ia (+) Cell and Neutrophil Counts and Glomerular LTB 4 Levels, $2 \mathrm{~h}$ after ER Administration

\begin{tabular}{|c|c|c|c|c|}
\hline & $\mathrm{WBC} \times 10^{3} / \mu \mathrm{l}$ & $\mathrm{Ia}(+)$ cells/glomerular & PMN/glomerular & $\mathrm{LTB}_{4}: \mathrm{ng} / \mathrm{mg}$ protein \\
\hline & Pre-ER 4 & 2 h Post-ER & 2 h Post-ER & 2 h Post-ER \\
\hline No irradiation $(n=10)$ & $10.45 \pm 0.4$ & $7.3 \pm 2.1$ & $5.0 \pm 0.7$ & $13.7 \pm 2.7$ \\
\hline $24 \mathrm{~h}$ post-irradiation $(n=8)$ & $2.20 \pm 0.7^{*}$ & $4.8 \pm 2.2$ & $1.6 \pm 0.5^{*}$ & $12.9 \pm 0.1$ \\
\hline $72 \mathrm{~h}$ post-irradiation $(n=6)$ & $1.90 \pm 0.4^{*}$ & $2.5 \pm 1.4^{*}$ & $1.4 \pm 0.4^{*}$ & $12.3 \pm 1.7$ \\
\hline $96 \mathrm{~h}$ post-irradiation $(n=6)$ & $1.97 \pm 0.3^{*}$ & $0.8 \pm 0.6^{*}$ & $2.1 \pm 0.3^{*}$ & $4.6 \pm 0.3^{*}$ \\
\hline
\end{tabular}

PMN, polymorphonuclear leukocyte. ${ }^{*} P<0.05$ compared with no irradiation.

donate lipoxygenation metabolites, HETE and leukotrienes have been best characterized $(6,10)$. Both vasoactive and proinflammatory roles have been attributed to these metabolites. Thus, antagonism of the $\mathrm{LTD}_{4}$ receptor prevents anti-glomerular basement membrane (GBM) antibody-mediated acute decrements in GFR (11), and essential fatty acid-deficient diets inhibit glomerular $\mathrm{LTB}_{4}$ synthesis and ameliorate the hemodynamic and histopathological severity of anti-GBM glomerular injury (12).

The cell of origin of "glomerular" eicosanoids has been an issue of debate. In antibody-mediated models of glomerular immune injury, it seemed reasonable to assume that the injured glomerular cell was a likely source of eicosanoids. This was a particularly reasonable assumption in models employing antibodies directed against antigens of specific glomerular cells (i.e., antibodies against the Fx $1 \mathrm{~A}$ antigen of glomerular epithelial cells) that, when cultured, were capable of eicosanoid synthesis. This assumption was strengthened further when the role of hematogenous cells capable of eicosanoid synthesis was assessed in infiltrative models of glomerular immune injury. Thus, in anti-GBM disease, an infiltrative form of experimental glomerulonephritis, it was demonstrated that platelets did not contribute to the enhanced glomerular 12-HETE synthesis (13) and, in the same disease model, neutrophil depletion only partially contributed to the enhanced glomerular $\mathrm{LTB}_{4}$ synthesis (6). Likewise, in a different model of infiltrative glomerulonephritis, induced by administration of cationized gamma globulin, enhanced glomerular $\mathrm{LTB}_{4}$ synthesis persisted in neutropenic rats (10). Several lines of evidence, however, indicate that cells other than those on which immunologic reactants (i.e., antibody and complement components) bind may account for the enhanced eicosanoid synthesis observed in glomeruli isolated after initiation of injury. (a) Isolated normal glomeruli

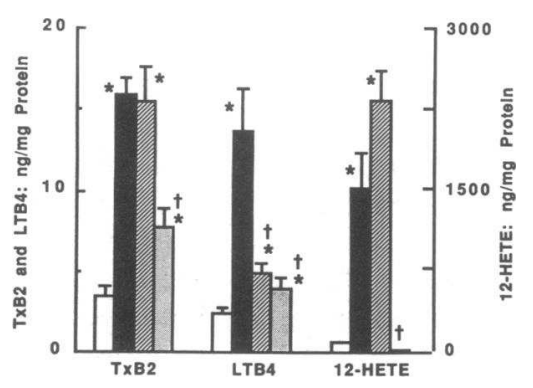

Figure 7. Effect of platelet depletion and of $\mathrm{x}$ irradiation $(96 \mathrm{~h}$ protocol) on glomerular $\mathrm{TxB}_{2}, \mathrm{LTB}_{4}$, and 12 HETE synthesis assessed at $2 \mathrm{~h}$ after $\mathbf{E R}_{\text {. }}$ antibody administration. $\mathrm{X}$ irradiation significantly reduced $\mathrm{LTB}_{4}$ synthesis only. Platelet depletion significantly

reduced $\mathrm{TxB}_{2}$ and $\mathrm{LTB}_{4}$ synthesis and abolished 12-HETE synthesis. Control (ם); $\mathrm{ER}_{4}(\square) ; \times$ irradiated (घ); platelet depleted (घ). ${ }^{*} P<0.05$ compared with controls. $\uparrow P<0.05$ compared with $\mathrm{ER}_{4}$. synthesize measurable amounts of $\mathrm{LTB}_{4}$ and 12-HETE when incubated with the phospholipase $A_{2}$ activator, $A_{23187}(6)$, yet, none of the glomerular cell populations in culture (epithelial, mesangial, endothelial) express the arachidonate 5-lipoxygenase gene $(14,15)$. (b) In glomerular epithelial cell injury mediated by anti-Fx1A antibody, there is enhanced glomerular $\mathrm{LTB}_{4}$ synthesis despite the fact that glomerular epithelial cells in culture do not synthesize $\mathrm{LTB}_{\mathbf{4}}$ and glomeruli do not show infiltration by leukotriene-producing cells (i.e., leukocytes) after anti-Fx1A administration (16). (c) Diets deficient in essential fatty acids, or bone marrow depletion using whole animal $x$ irradiation, abolish glomerular $\mathrm{LTB}_{4}$ synthesis, and this event was convincingly correlated with depletion of glomerular Ia-bearing monocytes (17), an observation that points to this cell type as a likely source of arachidonate lipoxygenation products in glomeruli.

On the basis of these controversial observations, we reasoned that because the eicosanoid synthetic profile of mesangial cells is well characterized (18) and the role of mesangial cells in regulating glomerular filtration emphasized (19), the model of anti-Thy 1 antibody-induced mesangial cell injury is most suitable to study origin and physiologic role of eicosanoids. The demonstration that the Thy- 1 antigen is specifically linked to membrane phosphatidylinositol in Thy-1-bearing cells (3), lends further suitability to this model of immune injury for study of the origin and role of eicosanoids.

Our observations indicate that in mesangial cell immune injury induced by the monoclonal anti-Thy 1 antibody ER cells other than the injured mesangial account for the enhanced glomerular eicosanoid synthesis. Moreover, different cells account for the synthesis of different eicosanoids. This is best illustrated in Fig. 4, where the dichotomy in the synthesis of the three arachidonate cyclooxygenation products, $\mathrm{PGE}_{2}, \mathrm{PGF} 2 \alpha$, and $\mathrm{TxB}_{2}$ is shown. This dichotomy is most apparent on day 4 , when $\mathrm{TxB}_{2}$ synthesis was at a maximum, while that of $\mathrm{PGE}_{2}$ and PGF $2 \alpha$ was at a minimum and at levels lower than controls. As the nadir in $\mathrm{PGE}_{2}$ and PGE2 $\alpha$ synthesis (Fig. 4) correlated with glomerular hypocellularity and mesangial cell depletion (Fig. $3 C$ ), we propose that the origin of these two eicosanoids is the mesangial cell. This contention is supported by the well established profile of eicosanoids in cultured mesangial cells that includes primarily $\mathrm{PGE}_{2}$ and PGF $2 \alpha(18)$. The recovery in $\mathrm{PGE}_{2}$ and PGF2 $\alpha$ synthesis on day 14 after administration of $\mathrm{ER}_{4}$ (Fig. 4) could be due to a mesangioproliferative phase (Fig. $3 D$ ), which follows the mesangiolytic phase as previously described in this model $(4,20)$.

That the Ia $(+)$ leukocyte is a likely source of glomerular $\mathrm{LTB}_{\mathbf{4}}$ is supported by the following two observations: (a) In $\mathrm{x}$ 

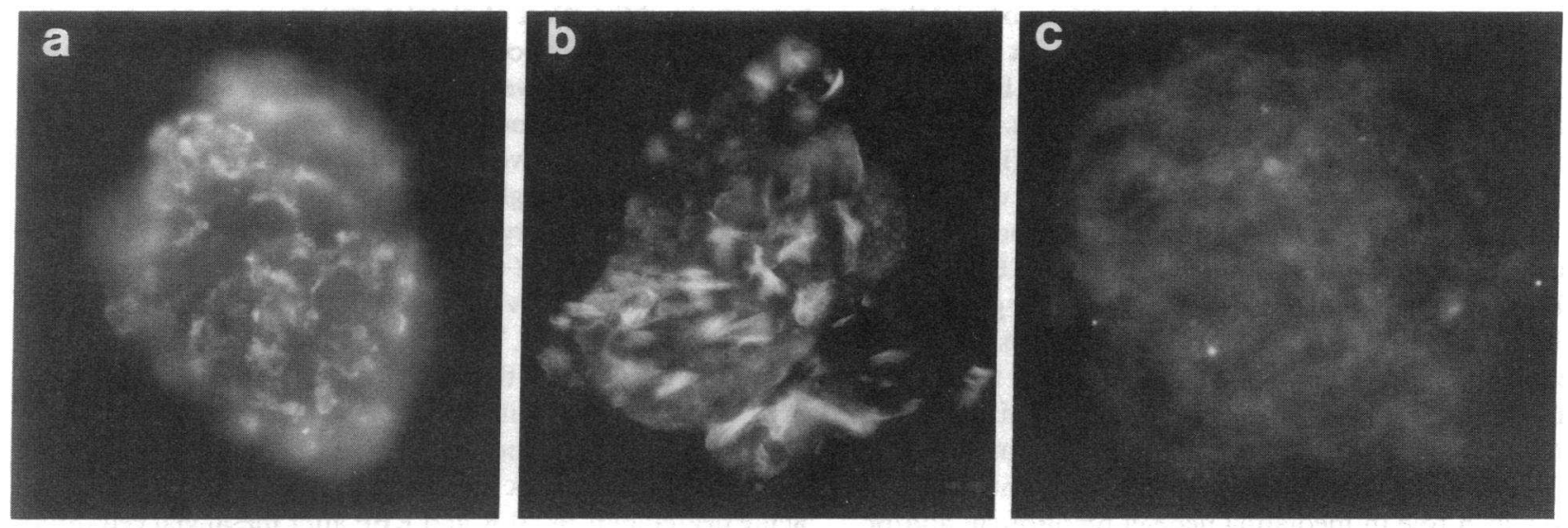

Figure 8. Binding of the $\mathrm{ER}_{4}$ antibody $(A)$ and rat $\mathrm{C}_{3}(B)$ in isolated enzymatically permeabilized normal glomeruli. $C$ is a control glomerulus stained for $\mathrm{C}_{3}$.

irradiated animals, enhanced glomerular $\mathrm{LTB}_{4}$ synthesis determined $2 \mathrm{~h}$ post-ER 4 continued in a manner independent of peripheral leukocyte counts and of glomerular neutrophil counts (Table I). It was abolished only in animals studied $96 \mathrm{~h}$ after $\mathrm{x}$ irradiation, when glomerular Ia $(+)$ cell counts were also abolished (Table I); $(b)$ binding of $\mathrm{ER}_{4}$ in permeabilized glomeruli (Fig. 8) originating from normal animals and in the presence of rat serum did not result in enhanced $\mathrm{LTB}_{4}$ or 12 HETE synthesis. Cell types possessing the Ia antigen that could account for the enhanced glomerular $\mathrm{LTB}_{4}$ synthesis include: elicited monocyte-macrophages, activated lymphocytes, activated glomerular endothelial cells, and the mesangial cell itself (21). As there is no evidence that lymphocytes synthesize 5HETE or $\mathrm{LTB}_{4}(22)$, or that glomerular epithelial, endothelial, or mesangial cells express the 5-lipoxygenase gene (14), we propose that the Ia $(+)$ monocyte-macrophage is the likely source of $\mathrm{LTB}_{4}$. Our observations do not entirely rule out the neutrophil as a potential source of $\mathrm{LTB}_{4}$. As shown in Figs. 5 and 6, the increments in glomerular $\mathrm{LTB}_{4}$ at 1 and $2 \mathrm{~h}$ coincided with

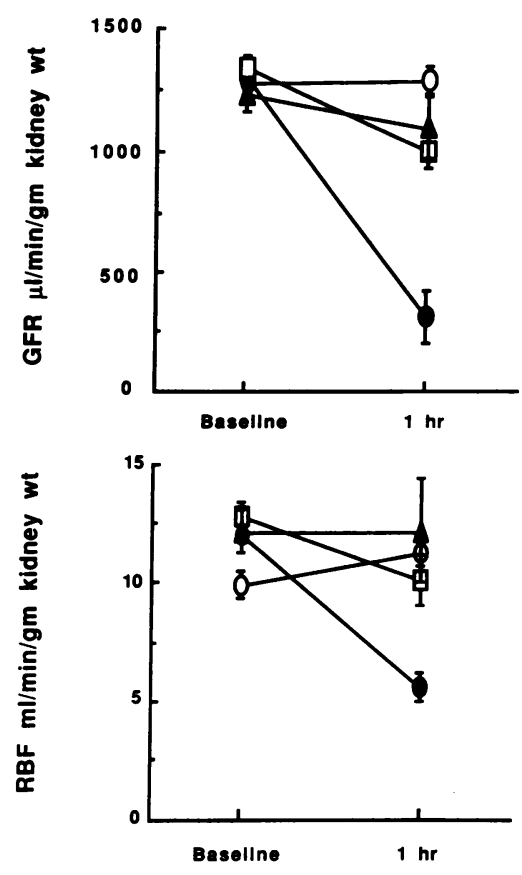

Figure 9. Effects of complement depletion and of pretreatment with the $\mathrm{TxA}_{2}$ receptor antagonist $\mathrm{SQ}-29,548$ on the decrements in GFR and RBF induced by administration of $\mathrm{ER}_{4}$. In the group pretreated with SQ-29,548, GFR and RBF were ameliorated to levels no different than those of the decomplemented group. There were no differences in GFR and RBF between complement replete $(n=6)$ and decomplemented rats $(n=6)$ that received mouse IgG. Decomplemented controls (-O), controls, $\mathrm{ER}_{4}(-\bullet-)$, decomplemented + ER $(-\square-)$, and SQ-29,548 $+\mathrm{ER}_{4}(-\Delta-)$. increments in both glomerular Ia $(+)$ and neutrophil counts. However, on days 4 and 14 after ER , LTB $_{4}$ synthesis returned toward control levels despite significant glomerular infiltration by neutrophils (Fig. 6). Moreover, in $\mathrm{x}$ irradiated leukopenic animals, glomerular depletion of neutrophils did not result in decreased glomerular $\mathrm{LTB}_{4}$ synthesis after $\mathrm{ER}_{4}$ (Table I). These observations indicate that the infiltrating neutrophil does not entirely account for the enhanced glomerular $\mathrm{LTB}_{4}$ synthesis after administration of $E_{4}$. The reason for the discrepancy between glomerular Ia ( + ) and neutrophil cell counts and $\mathrm{LTB}_{4}$ levels on days 4 and 14 (Figs. 5 and 6) is not clear. Specifically,

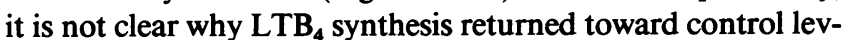
els despite the sustained increase in glomerular Ia (+) and neutrophil counts. A similar phenomenon was previously described in anti-GBM antibody-induced injury, an infiltrative type of glomerular immune injury, in which the enhancement in glomerular $\mathrm{LTB}_{4}$ synthesis was again short lived and did not correlate with glomerular neutrophil infiltration (6).

The enhanced glomerular $\mathrm{LTB}_{4}$ synthesis was complement dependent (Table II) and this might be accounted for by the effect of complement activation and anaphylatoxin release on glomerular leukocyte infiltration. In addition, it is possible that binding of anaphylatoxin (C5a), generated after intraglomerular complement activation, on Ia-bearing macrophages results in enhanced $\mathrm{LTB}_{4}$ synthesis either directly or via a mechanism involving IL-1. Specific receptors for C5a have been demonstrated on murine Ia-bearing macrophages and binding of C5a on these receptors induces IL-1 secretion (23). IL-1, in turn, is a known eicosanoid synthesis agonist.

Table II. Glomerular Eicosanoid Synthesis (ng/mg Glomerular

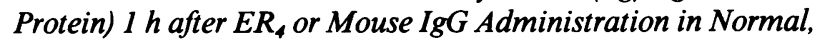
Decomplemented (CVF $+E R$ ), and Tx Receptor Antagonist (SQ-29,548 +ER $)$-pretreated Rats

\begin{tabular}{lcccc}
\hline & Controls & $\mathrm{ER}_{4}$ & $\mathrm{CVF}+\mathrm{ER}_{4}$ & $\mathrm{SQ}-29,548+\mathrm{ER}_{4}$ \\
\hline & $n=6$ & $n=8$ & $n=8$ & $n=6$ \\
$\mathrm{TxB}_{2}$ & $4.9 \pm 0.6^{*}$ & $11.4 \pm 1.0$ & $7.4 \pm 1.1^{*}$ & $14.4 \pm 2.0$ \\
$\mathrm{LTB}_{4}$ & $0.7 \pm 0.1^{*}$ & $11.4 \pm 2.6$ & $4.9 \pm 0.8^{*}$ & $11.1 \pm 3.0$ \\
$12-\mathrm{HETE}$ & $46 \pm 12^{*}$ & $988 \pm 75$ & $263 \pm 57^{*}$ & $1532 \pm 308$ \\
& & & & \\
\end{tabular}

* $P<0.05$ compared with $\mathrm{ER}_{4}$. 
The dependence of glomerular $\mathrm{LTB}_{4}$ synthesis on platelets is intriguing (Fig. 7), mainly because platelets do not synthesize LTB $_{4}$. Thus, this observation raises the possibility for a platelet/leukocyte interaction resulting in $\mathrm{LTB}_{4}$ synthesis. The platelet could generate an eicosanoid synthesis agonist (i.e., PDGF or TGF- $\beta$ ). It may provide arachidonate, which can subsequently undergo 5-lipoxygenation to $\mathrm{LTB}_{4}$ by 5-lipoxygenasecontaining leukocytes (24), or it may augment $\mathrm{LTB}_{4}$ production by leukocytes through a mechanism involving generation of 12-HPETE (25). In the latter case, however, one would expect the enhanced glomerular 12-HETE synthesis to preceed that of $\mathrm{LTB}_{4}$, an event that was not noted in our time course studies (Fig. 5), which demonstrate that the enhanced LTB $_{4}$ synthesis preceeded that of 12-HETE. The complement system may also play a role in mediating platelet recruitment and/or activation, thereby promoting platelet-leukocyte interactions. In mesangial cell injury induced by a polyclonal rabbit anti-rat thymocyte antibody, it was demonstrated that complement depletion using CVF reduced glomerular platelet infiltration (26). As can be concluded from Fig. 7, platelets accounted for the glomerular 12-HETE and $\mathrm{TxB}_{2}$ synthesis. Of these two eicosanoids, the effect on 12-HETE was the most striking. In contrast, $\mathrm{TxB}_{2}$ levels remained elevated compared with controls. In contrast to platelet depletion, $x$ irradiation, followed by a 96-h waiting period, had no effect on glomerular $\mathrm{TxB}_{2}$ or 12HETE synthesis (Fig. 7). As this $x$ irradiation protocol depletes glomeruli of Ia-bearing monocytes (reference 8 and Table I), our observations indicate that this cell population does not entirely account for the sustained increments in glomerular $\mathrm{TxB}_{2}$ or 12-HETE synthesis after administration of $\mathrm{ER}_{4}$. This contrasts with the observations of Stahl and co-workers, who reported a monocyte dependence of glomerular $\mathrm{TxB}_{2}$ synthesis in a model of mesangial cell injury using rabbit polyclonal antibody against the rat thymocyte (27). This discrepancy could be due to the different experimental approaches employed in order to deplete monocytes, namely, immune monocytopenia (27) versus $\mathrm{x}$ irradiation, which causes bone marrow depletion and progressive glomerular Ia (+) cell depletion.

Our data indicate that the protective effect of complement depletion on GFR and RBF was associated with decreased glomerular synthesis of $\mathrm{TxB}_{2}, \mathrm{LTB}_{4}$, and 12-HETE (Table II). The protective effect of decomplementation can be accounted for by the decrements in thromboxane synthesis, as pretreatment with the $\mathrm{TxA}_{2}$ receptor antagonist SQ-29,548 ameliorated the $\mathrm{ER}_{4}$-induced decrements in GFR to an extent similar to that noted in decomplemented animals (Fig. 9) and had no effect on $\mathrm{TxB}_{2}, \mathrm{LTB}_{4}$, or 12-HETE synthesis (Table II). That thromboxane mediates the acute decrements in GFR is also supported by the recent observations of Stahl and co-workers, who demonstrated that thromboxane synthase inhibition ameliorated the anti-thymocyte antibody-induced decrements in GFR (27). Whether the enhanced synthesis of $\mathrm{LTB}_{4}$ or 12HETE have a vasoactive effect and contribute to the decrements in GFR is speculative. A synergistic effect to thromboxane is likely because 12-HETE has recently been shown to vasoconstrict the rat vasculature (28) and essential fatty acid-deficient diets inhibit glomerular $\mathrm{LTB}_{4}$ and ameliorate decrements in GFR and RBF in glomerular immune injury induced by anti-GBM antibody (12). The availability of specific 12-lipoxygenase or 5-lipoxygenase inhibitors should allow definitive conclusions to be made on the role of 12-HETE and $\mathrm{LTB}_{4}$ in mediating the decrements in GFR and RBF. More- over, study of the effect of platelet depletion on renal hemodynamic perturbations occurring in mesangial cell immune injury would allow unravelling of the role of platelet-derived vasoactive eicosanoids, such as $\mathrm{Tx}$ and 12-HETE.

In summary, we have demonstrated that the enhanced synthesis of eicosanoids in glomeruli isolated from rats with mesangial cell immune injury originates from cells other than the mesangial cell. The Ia (+) leukocyte is a likely source of LTB $_{4}$ by a mechanism involving interactions with the complement system and the platelet. The stimulus for $\mathrm{LTB}_{4}$ synthesis, however, is short lived and the participation of the neutrophil cannot be entirely ruled out. The platelet entirely accounts for the enhanced 12-HETE and partially accounts for the enhanced thromboxane synthesis. Complement activation mediates the acute decrements in GFR and RBF after mesangial cell injury via a mechanism involving enhanced eicosanoid synthesis and specifically thromboxane.

Our observations are of significance in that they implicate the platelet and the leukocyte as sources of proinflammatory and vasoactive eicosanoids in mesangial cell immune injury. Both cell types are capable of synthesizing and releasing potent noneicosanoid proinflammatory factors that can mediate proliferation (i.e., PDGF), matrix synthesis (i.e., TGF- $\beta$ ), cytotoxicity (i.e., TNF), and immunoregulation (interleukins). The timed or sustained synthesis of specific eicosanoids by these cells may, therefore, play an important role in regulating the synthesis or release of these proinflammatory factors in an autocrine or paracrine manner.

\section{Acknowledgments}

Cindy Ziebell provided expert secretarial assistance.

This work was supported by a United States Public Health Service Grant, RO1-DK-34793, and an American Heart Established Investigatorship to Dr. Lianos, and a United States Public Health Service National Research Service Award F32-DK-08243 to Dr. Bresnahan.

\section{References}

1. Crawford, J. M., and R. W. Barton. 1986. Thy-1 glycoprotein: structure distribution, and ontogeny. Lab. Invest. 54:122-135.

2. Paul, L. C., H. G. Rennke, E. L. Milford, and C. B. Carpenter. 1984. Thy-1.1 in glomeruli of rat kidneys. Kidney Int. 25:771-777.

3. Low, M. G., and P. W. Kincade. 1985. Phosphatidylinositol is the membrane-anchoring domain of the Thy-1 glycoprotein. Nature (Lond.). 318:62-64.

4. Bagchus, W. M., Ph.J. Hoedemaeker, J. Rozing, and W. W. Bakker. 1986. Glomerulonephritis induced by monoclonal anti-Thy 1.1 antibodies. Lab. Invest. 55:680-687.

5. Lianos, E. A., G. Andres, and M. J. Dunn. 1983. Glomerular prostaglandin and thromboxane synthesis in rat nephrotoxic serum nephritis. Effects on renal hemodynamics. J. Clin. Invest. 72:1439-1448.

6. Lianos, E. A. 1988. Synthesis of hydroxyeicosatetraenoic acids and leukotrienes in rat nephrotoxic serum glomerulonephritis. Role of anti-glomerular basement membrane antibody dose, complement and neutrophiles. J. Clin. Invest. $82: 427-435$.

7. Till, G. O., K. J. Johnson, R. Kunkel, and P. A. Ward. 1982. Intravascular activation of complement in acute lung injury. Dependency on neutrophils and toxic oxygen metabolites. J. Clin. Invest. 69:1126-1135.

8. Schreiner, G., and E. R. Unanue. 1984. Origin of the rat mesangial phagocyte and its expression of the leukocyte common antigen. Lab. Invest. 51:515523.

9. Lianos, E. A. 1989. Eicosanoids and the modulation of glomerular immune injury. Kidney Int. 35:985-992.

10. Rahman, M. A., M. Nakazawa, S. N. Emancipator, and M. J. Dunn. 1988 Increased leukotriene $\mathrm{B}_{4}$ synthesis in immune injured rat glomeruli. J. Clin. Invest. 81:1945-1952.

11. Badr, K. F., G. F. Schreiner, M. Wasserman, and I. Ichikawa. 1988. Preservation of the glomerular capillary ultrafiltration coefficient during rat 
nephrotoxic serum nephritis by a specific leukotriene $D_{4}$ receptor antagonist. $J$. Clin. Invest. 81:1702-1709.

12. Takahashi, K., G. F. Schreiner, J. B. Lefkowith, and K. F. Badr. 1990 Essential fatty acid deficiency normalizes glomerular functions and suppresses leukotriene/thromboxane synthesis in nephrotoxic serum nephritis. Kidney Int. 37:352a. (Abstr.)

13. Lianos, E. A., M. A. Rahman, and M. J. Dunn. 1985. Glomerular arachidonate lipoxygenation in rat nephrotoxic serum nephritis. J. Clin. Invest. 76:1355-1359.

14. Imai, E., R. L. Hoover, N. Makita, C. D. Funk, and K. F. Badr. 1990. Localization and relative abundance of 5-lipoxygenase, 15-LO, 12-LO, and leukotriene $\mathrm{A}_{4}$ hydroxylase gene expression in cultured glomerular cells. J. Am. Soc Nephrol. 1:443a. (Abstr.)

15. Garrick, R., S. T. Shen, S. Ogunc, and P. Y.-K. Wong. 1990. Reciprocal relationship of lipoxins and leukotriene $\mathrm{B}_{4}$ in rat mesangial cells. Kidney Int. 37:368a. (Abstr.)

16. Lianos, E. A., and B. Noble. 1989. Glomerular leukotriene synthesis in Heymann nephritis. Kidney Int. 36:998-1002.

17. Lefkowith, J. B., A. R. Morrison, and G. F. Schreiner. 1988. Murine glomerular leukotriene $B_{4}$ synthesis. Manipulation by $(n-6)$ fatty acid deprivation and cellular origin. J. Clin. Invest. 82:1655-1660.

18. Scharschmidt, L., and M. J. Dunn. 1983. Prostaglandin synthesis by rat glomerular mesangial cells in culture. The Effects of angiotensin II and arginine vasopressin. J. Clin. Invest. 71:1756-1764.

19. Dworkin, L. D., I. Ichikawa, and B. M. Brenner. 1983. Hormonal modulation of glomerular function. Am. J. Physiol. 244:F95-F104.

20. Bagchus, W. M., M. E. Jeunink, and J. D. Elema. 1990. The mesangium in anti-Thy 1 nephritis. Influx of macrophages, mesangial cell hypercellularity and macromolecular accumulation. Am. J. Pathol. 137:215-223.

21. Martin, M., R. Schwinzer, H. Schellekens, and K. Resch. 1989. Glomerular mesangial cells in local inflammation. Induction of the expression of MHC Class II antigens by IFN- $\gamma$. J. Immunol. 142:1887-1894.

22. Goldyne, M. E., G. F. Burrish, P. Poubelle, and P. Borgeat. 1984. Arachidonic acid metabolism among human mononuclear leukocytes: lipoxygenase-related pathways. J. Biol. Chem. 259:8815-8819.

23. Goodman, M. G., D. E. Chenoweth, and W. O. Weigle. 1982. Induction of interleukin-1 secretion and enhancement of human immunity by binding of human C5a to macrophage surface C5a receptors. J. Exp. Med. 1156:912-917.

24. Marcus, A. J., M. J. Broekman, L. B. Safier, H. L. Ullman, N. Islam, C. N. Sherhan, L. E. Rutherford, H. M. Korchak, and G. Weissman. 1982. Formation of leukotrienes and other hydroxy acids during platelet-neutrophil interactions in vitro. Biochem. Biophys. Res. Commun. 101(1):130-137.

25. Maclouf, J., B. Fruteau de Laclos, and P. Borgeat. 1982. Stimulation of leukotriene biosynthesis in human blood leukocytes by platelet-derived 12-hydroperoxy-icosatetranoic acid. Proc. Natl. Acad. Sci. USA. 79:6042-6046.

26. Couser, W. G., C. Alpers, P. Baker, and R. Johnson. 1990. Complement dependent localization of platelets in antibody mediated mesangial proliferative nephritis. Kidney Int. 37:412a. (Abstr.)

27. Stahl, R. A. K., F. Thaiss, S. Kahf, W. Schoeppe, and U. M. Helmchen. 1990. Immune-mediated mesangial cell injury-Biosynthesis and function of prostanoids. Kidney Int. 38:273-281.

28. Yunn-Hwa, M., D. R. Harder, J. E. Clark, and R. J. Roman. 1991. Effects of 12-hydroxyeicosatetraenoic acid (12-HETE) on isolated dog renal arcuate arteries. Am. J. Physiol. In press. 